\title{
El topiramato fue beneficioso para la prevención de la migraña
}

\section{Objetivo:}

Evaluar la eficacia y seguridad del topiramato en la prevención de la migraña.

Diseño:

Ensayo clínico controlado aleatorizado, doble ciego.

Lugar:

Participaron 52 centros médicos de Estados Unidos.

\section{Pacientes:}

Se incluyeron pacientes con historia de por lo menos 6 meses de migraña con y sin aura de acuerdo a criterios de la Sociedad Internacional de Cefaleas, de edades comprendidas entre 12 y 65 años y con un mínimo de crisis de dolor entre 3 y 12 por mes y no más de 15 en el mes.

\section{Intervención:}

Se aleatorizaron 483 pacientes en 4 grupos: un grupo recibió placebo y tres grupo topiramato, en dosis de 50,100 y $200 \mathrm{mg}$. El topiramato se titulaba aumentando de a $25 \mathrm{mg}$ por semana hasta la dosis asignada o tolerada. El seguimiento fue de 6 meses.

\section{Medición de los resultados principales}

De los 483 pacientes aleatorizados, se incluyeron 468 en el análisis por intención de tratar. Se evaluó como resultado primario las diferencias en la tasa media de episodios de migrañas por mes entre los distintos grupos de intervención. Medición de resultados secundarios: Tasa de respondedores (definida como disminución de al menos $50 \%$ en el número de episodios mensuales), severidad, intensidad y duración de los episodios, número de días requeridos de medicación de rescate por mes.

\section{Resultados principales:}

Se observa en la tabla la comparación del cambio en la frecuencia mensual de episodios de migraña entre el comienzo y final del estudio para cada uno de los grupos de topiramato en relación al placebo.

Tabla: Frecuencia de Migrañas (Promedio de episodios por mes)

\begin{tabular}{l|c|c|c|c} 
& \multirow{2}{*}{} & Placebo & $\mathbf{3}$ & \multicolumn{3}{|c}{ Topiramato } \\
\cline { 3 - 5 } & & $\mathbf{5 0} \mathbf{~ m g / d a}$ & $\mathbf{1 0 0} \mathbf{~ m g / d a}$ & $\mathbf{2 0 0} \mathbf{~ m g / d a}$ \\
\hline Inicio del estudio & 5,6 & 5,4 & 5,8 & 5,1 \\
\hline Final del estudio & 4,5 & 4,1 & 3,5 & 3,0 \\
\hline & NS & $\mathrm{P}=\mathrm{NS}$ & $\mathrm{P}=0,008$ & $\mathrm{P}=<0,001$ \\
\hline
\end{tabular}

Como se observa, la frecuencia promedio de migraña se redujo significativamente en los pacientes que recibieron $100 \mathrm{mg} /$ día de topiramato $(-2,1 ; p=0,008)$ y $200 \mathrm{mg} /$ día $(-2,4 ; P<.001)$, mientras que no se observó un efecto significativo con placebo o $50 \mathrm{mg} / \mathrm{dí}$ a de topiramato. La tasa de respondedores en los grupos topiramato fue superior al grupo placebo (23\%): $50 \mathrm{mg} /$ día $(39 \%, p=0,01), 100$ $\mathrm{mg} / \mathrm{día}(49 \%, \mathrm{p}<0,001)$, y $200 \mathrm{mg} / \mathrm{día}(47 \%, \mathrm{p}<0,001)$. La reducción de días con migraña, y el menor uso de medicacion de rescate fueron observados en los grupos de 100 y $200 \mathrm{mg} / \mathrm{día}$. Efectos adversos que resultaron en el abandono del topiramato incluyeron parestesias, fatiga y nauseas.

\section{Conclusiones:}

El topiramato (100-200 mg/día) mostró una eficacia significativa en la prevención de migrañas dentro del mes de tratamiento, y el efecto se mantuvo a los seis meses de seguimiento

Fuente de financiamiento: Johnson \& Johnson Pharmaceutical Research and Development, LLC.

\section{Comentario}

La migraña es por su alta prevalencia, su significativa discapacidad y su estrecha asociación con síntomas neurológicos o gastrointestinales un importante motivo de consulta en la práctica ambulatoria. En un artículo donde se evalúa su prevalencia en Atención Primaria se halló que el $90 \%$ de las consultas por cefalea corresponden a pacientes que reúnen criterios para migraña según lo establecido por la Sociedad Internacional de Cefaleas, mientras que sólo un $3 \%$ presentan cefalea tensional episódica'.

Este estudio demuestra que el topiramato podría incluirse en la clase I de fármacos preventivos de la migraña (junto con propranolol, amitriptilina y valproato) ${ }^{2}$ debido a que permitió reducir la frecuencia de crisis de ambos tipos de migraña en un $50 \%$ en el pe- riodo que duró el ensayo clínico.

La droga fue segura y en general bien tolerada, con efectos adversos dependientes de las dosis, como por ejemplo descenso de peso, parestesias, etc.

\section{Conclusión del comentador:}

El topiramato sería un nuevo recurso farmacológico en la prevención de la migraña. Para lograr una mayor aceptación del paciente al tratamiento es necesaria una lenta titulación a razón de $12,5 \mathrm{mg}$ de topiramato por semana, hasta lograr los objetivos propuestos y también de esta manera disminuir la probabilidad de efectos adversos, muy relacionados con la dosis.

Prof. Dr. Daniel Doctorovich [ Jefe Sección de Cefaleas Servicio de Neurología Hospital Italiano de Buenos Aires ]

Doctorovich D. El topiramato fue beneficioso para la prevención de la migraña. Evid. actual. práct. ambul 2004;7:102. Comentado de: Brandes J, Saper R, Diamond M, y cols. Topiramate for migraine prevention: A randomized controlled trial. JAMA.2004; 291:965-973.

\section{Referencias}

1.Dowson A, Dahlof C, Tepper S, Newman L. Prevalence and diagnosis of migraine in a primary care setting. Cephalalgia. 2000; $22: 590$.

2.Silberstein SD. Practice parameter: evicence-based guidelines for migraine headache (an evidence based review): report of the Qualitiy Standards Subcommittee of The American Academy of Neurology. Neurology. 2000; 59:1011-1014. 